\title{
Bubonic Plague Outbreak Investigation in the Endemic District of Tsiroanomandidy - Madagascar, October 2014
}

\section{Rakotoarisoa $\mathrm{A}^{* 1,2,3}$, Ramihangihajason $\mathrm{T}^{5}$, Ramarokoto $\mathrm{C}^{2}$, Rahelinirina $\mathrm{S}^{4}$, Halm $\mathrm{A}^{6}$, Piola $\mathrm{P}^{2}$, Ratsitorahina $\mathbf{M}^{1,2}$ and Rajerison $\mathbf{M}^{4}$}

${ }^{1}$ Epidemiological Surveillance Department, Ministry of Health, Madagascar

${ }^{2}$ Epidemiology Unit, Pasteur Institute Madagascar

${ }^{3}$ Epidemiology Training Program, Indian Ocean Commission (FETP-IOC), Mauritius

${ }^{4}$ Plague Unit, Pasteur Institute Madagascar

${ }^{5}$ Entomology Unit, Pasteur Institute Madagascar

${ }^{6}$ Health Surveillance Unit, Indian Ocean Commission, Mauritius

${ }^{*}$ Corresponding author: Rakotoarisoa A, Directorate of Health Surveillance and Epidemiological Surveillance (DVSSE) Ministry of Public Health, Precinct INSPC, Mahamasina, Antananarivo CP:101, Madagascar, Tel: +261 3409233 64, E-mail: arissoa@gmail.com

Citation: Rakotoarisoa A, Ramihangihajason T, Ramarokoto C, Rahelinirina S, Halm A, et al. (2016) Bubonic Plague Outbreak Investigation in the Endemic District of Tsiroanomandidy - Madagascar, October 2014. J Case Rep Stud 5(1): 103. doi: 10.15744/2348-9820.5.103

Received Date: September 30, 2016 Accepted Date: February 24, 2017 Published Date: February 27, 2017

\begin{abstract}
Background: Plague remains a major public health problem in Madagascar. Faced with reports of plague cases and deaths in Tsiroanomandidy district, we performed an investigation in October 2014.

Our aim was to describe the plague outbreak and to improve the national plague control strategies.

Methods: We used the National plague control program case definition. We identified cases from outpatient registers and collected socio-demographic and clinical information. Plague circulation was determined through a retrospective environmental survey of rodents and vectors.

Results: From August 1st to October $12^{\text {th }}$ 2014, we identified 30 cases of which 13 deaths in 7 out of 17 municipalities; 18 were confirmed, 6 probable, and 6 suspected cases. The sex ratio (M/F) was 4:1. Yersinia pestis was isolated from Rattus rattus in one municipality. Flea index was 2.3. We collected 45 fleas through a trap set in a house 6 hours after insecticide spraying.

Conclusion: The presence of infected flea and rodent maintain the persistence of plague in the municipalities investigated. There is a high risk of plague transmission to humans. This study showed that rodent and flea information are important for plague control strategies.

Keywords: Bubonic Plague; Outbreak; Environmental Factors; Reservoirs; Vectors

List of Abbreviations: BHCS: Basic Health Center; CDC: Control and prevention Diseases Center; DHS: District Health Service; IPM: Institut Pasteur de Madagascar; MOH: Ministry of Health; SMZ-TMP: Sulfamethoxazole Trimethoprim; WHO: World Health Organization
\end{abstract}

\section{Introduction}

Plague is a zoonotic disease caused by the bacillus Yersinia pestis, rodents are reservoirs and the disease is transmitted by infected fleas or by direct exposure. Symptoms associate high fever with painful bubo, chills, headache, malaise, prostration, hemoptysis and pneumonia. The clinical forms are bubonic, septicemia or pneumonia. Bubonic plague is treated by a combination of injected streptomycin and oral sulfamethoxazole trimethoprim [1-3].

In the world, 3248 cases of plague in humans were reported from 2010 to 2015, resulting in 584 deaths [4].

Madagascar is the most seriously affected country in the world with $74 \%$ of the total cases in the world [4]. Plague is endemic in Madagascar with the number of reported human cases ranging from 312 to 648 per year between 2010 and 2014 [4]. Plague season usually starts in September and ends in April. It primarily affects the central highlands, with an elevation over 800 m [5,6]. Plague is a mandatory notification disease with an individual form provided by the Ministry of health National plague control program [7]. Human infections occur in households during an epizootic among rats living in or near human dwellings and animal facilities. 
Tsiroanomandidy is a plague-endemic district located $212 \mathrm{~km}$ from the capital Antananarivo in the Midwest of Madagascar. During this period: August $1^{\text {st }}$ (beginning of the plague season in Madagascar) to October $12^{\text {th }}$ (end of the investigation), plaguecases were reported in 7 out of 17 municipalities of the district. The district has 1 reference hospital and 30 basic health centers (BHCS). In Madagascar, plague epidemics occur from August to April, with peaks in December and January corresponding to the maximum of precipitation.

According to the data base of Pasteur Institute Madagascar, from 2008 to 2014, the five municipalities that recorded a total number of plague cases over 40 cases were: Tsiroanomandidy fihaonana, Miandrarivo, Ankadinondry sakay, Tsinjoarivo Imanga and Ambatolampy. The total number of plague cases in the district of Tsiroanomandidy was almost constant during the previous three years, from 2011 to 2013.

Confronted with the notification of suspected plague cases and deaths reported by the local health authority of Tsiroanomandidy district in late September 2014 and according to the District Health Service (DHS) register, from August $1^{\text {st }}$ (the beginning of the 2014-2015 plague season) to October $9^{\text {th }} 2014$ (week 32 to week 41), 27 out of 30 (90\%) plague cases were notified in two out of 17 municipalities, namely Tsinjoarivo Imanga and Ambatolampy.

A team from the Pasteur Institute de Madagascar (IPM) was sent to perform rodent capture and a disinfestation campaign while a team of epidemiologists conducted a plague outbreak investigation from October $10^{\text {th }}$ to $14^{\text {th }}$. The joint investigation team consisted of epidemiologists, rodentologists and entomologists technicians.

The objectives of our investigation were i) to conduct active cases and contacts finding; ii) to describe all cases; iii) to raise hypotheses about exposure factors and finally; iv) to strengthen the local health team in order to block the spread of this epidemic and prevent new outbreaks.

\section{Methods}

We conducted an investigation and descriptive analysis study

\section{Case definition according to the National Plague program}

A suspected bubonic plague case was defined as any person with uncorrected axillary temperature above $37^{\circ} 5$ Celsius associated with bubo(es) in a favorable epidemiological context (contact with a case or residence or travel in endemic areas or observed/ reported prior rat mortality or evidence of flea bite from September $27^{\text {th }} 2014$ ).

A probable case was defined as a suspected case with positive F1 antigen dipstick rapid test. The detection of F1 antigen in the diagnosis of plague during the acute phase of the disease is quite relevant in both human and rodents [8]. Confirmed case was defined as any suspected or probable case of plague with a positive Yersinia pestis culture.

\section{Case finding}

We examined the outpatients' registers of the BHCS and all individual notification forms issued by the DHS.

New cases detected during our mission were identified by consulting the registers of the BHCS and by conducting active research. All cases that occurred until September $27^{\text {th }}$ and new cases reported during our investigation period were included. Active research consist in conducting an interview and medical examination of persons who have been in contact with a case, the aim was to identify new suspected cases among families and their neighbors.

\section{Data collection}

We interviewed each identified case and/or their relatives using a standardized questionnaire. The form included demographic information as well as data regarding the clinical details of the disease, residence or visit in an endemic area within the 10 days before the onset of symptoms, contact with a suspected plague case or deceased, rat mortality in or around households or in the fields. The identified contacts were given sulfamethoxazole trimethoprim (STX TMP) as chemoprophylaxis, free of charge. New cases detected were treated by injectable streptomycin and all treated patients responded favorably to antibiotic therapy.

An environmental survey was conducted among heads of family cases, neighbors and community workers to identify risk factors for the disease including the possible mortality or proliferation of rodents and fleas, the practice of bush fires, the unsafe environment. Tsiroanomandidy the site of study is located in $18^{\circ} 4$ South to $46^{\circ} 3$ East.

Rodents have been trapped in 5 hamlets where human cases have occurred. Forty live traps were distributed randomly in 20 houses and indoor for each hamlet. Body weight as well as length measurements of rodents were recorder in order to identify the species and their age. Rodent spleen samples were collected from rodent captured following the Pasteur Institute guidelines [9] in order to detect Yersinia pestis by culture on median agar. Rodent fleas were collected to calculate flea index (number of flea per animal).

To reduce density of rodent-fleas vectors, the insecticide fenithrothion was used by using bait box kartman and Matabi sprayer. Free fleas were collected by using light traps. 
The first goal was to calculate the rodent density in the area (number of rodents per species per hamlets) and the flea index (total number of fleas collected, divided by the total number of rodents captured). The second goal was to perform rat spleen sampling for subsequent isolation of Y.pestis.

The insecticide used was fenitrothion ${ }^{\mathrm{Tm}}$ using Matabi $^{\mathrm{Tm}}$ sprayer. We used candle flea traps to test the effectiveness of the pesticide, consisting of a plate filled with water or salt or detergent and a lit candle and in its middle to attract fleas.

\section{Data analysis}

Means and medians were used as measures of central tendency and statistical analysis was implemented using Epi info 7.1.5.0 (CDC Atlanta). Statistical test used is the Chi 2 test for comparison of proportions or Fisher exact for small cell numbers. We used a 95\% confidence interval and considered a p- value below 0.05 as significant.

The number of general population used as a denominator data was drawn from the data base of National Institute of Statistics of Madagascar (INSTAT. 2014) and the Demographic and Health Surveys Madagascar (EDSM IV. 2009) [10].

\section{Results}

\section{Case identification}

The outbreak started on week 32 and finished on week 41, there were peaks in week 37, 39 and 41. Over an 11 week period, we identified 30 cases of bubonic plague of which 18 confirmed cases, 6 probable cases and 6 suspect cases. Cases were distributed along 9 weeks while the 13 deaths occurred within 6 weeks (Week 36 to Week 41) (Table 1). There were 10 deaths among confirmed cases and 3 deaths among probable cases given a total of 13 deaths (case fatality rate of $41.9 \%$ ) linked to plague in the district of Tsiroanomandidy.

\begin{tabular}{|c|c|c|c|c|c|c|c|c|c|c|c|c|}
\hline \multicolumn{2}{|c|}{ Week/lab \& status } & W32 & W33 & W34 & W35 & W36 & W37 & W38 & W39 & W40 & W41 & Total \\
\hline \multirow{2}{*}{ Suspect } & Alive & - & - & - & - & 2 & 1 & - & 2 & 1 & - & 6 \\
\hline & Deceased & - & - & - & - & - & - & - & - & - & - & - \\
\hline \multirow{2}{*}{ Probable } & Alive & 1 & - & - & - & - & 1 & - & - & 1 & - & 3 \\
\hline & Deceased & - & - & - & 1 & - & - & - & - & - & 2 & 3 \\
\hline \multirow{2}{*}{ Confirmed } & Alive & - & - & 1 & - & 1 & - & 1 & 2 & - & 2 & 7 \\
\hline & Deceased & - & - & - & 1 & 0 & 5 & 0 & 2 & 1 & 2 & 11 \\
\hline Total & & 1 & 0 & 1 & 2 & 3 & 7 & 1 & 6 & 3 & 6 & 30 \\
\hline
\end{tabular}

Table 1: Plague cases and deaths in the district of Tsiroanomandidy, August 1st until October 12th, 2014 (week 32 to week 41) $(\mathrm{n}=30)$

New suspected cases were detected among families and neighbors of cases: 2 cases in the municipality of Ambatolampy and then 3 death cases in the municipalities of Tsinjoarivo Imanga, these two municipalities are well known as plague endemics foci (Table 2).

\begin{tabular}{|c|c|c|c|c|c|}
\hline \multirow{2}{*}{$<\mathbf{1 5}$ years } & Number & Total & \% & P value \\
\cline { 2 - 5 } & Cases & 17 & 30 & 56.6 & \multirow{2}{*}{$P=0.19$} \\
\cline { 2 - 5 } Male & General population (EDSM 2009) & 36748 & 81867 & 44.9 & \\
\cline { 2 - 5 } & Cases & 24 & 30 & 80 & \multirow{2}{*}{$P=0.0009$} \\
\cline { 2 - 5 } & General population (EDSM 2009) & 40779 & 81867 & 49.8 & \\
\hline
\end{tabular}

Plague case distribution according to the age group and sex

Table 2: Distribution of plague cases according to age group and sex

Median age of the cases was 13.5 years (range: 5 to 45 years) and 56.6\% (17/30) of cases were under 15 years.

There were no significant differences between the proportions of cases in the age group below 15 years old (56.6\%) compared to the general population $(44.9 \%)(p=0.19)$.

The proportion of males among the cases $(80 \%)$ is significantly higher than the general population $(49.8)(P<0.001)$.

Ninety percent (27/30) of cases occurred in two municipalities (Tsinjoarivo and Ambatolampy) (Figure 1). Table 1 shows the distribution of all cases in each municipality. The outbreak started on week 32 in the municipality of Tsinjoarivo, and the peak was in week 37. During this period, 7 out of the 17 municipalities of Tsiroanomandidy reported cases of plague (Figure 2).

Five new cases among which three deceased were reported in the two municipalities of Tsinjoarivo and Ambatolampy during the term of our investigation.

Cohabitation with animals and generalized poor sanitation were commonly observed in the 5 hamlets visited. Bushfires exist every year, especially during the summer season (September to November) 


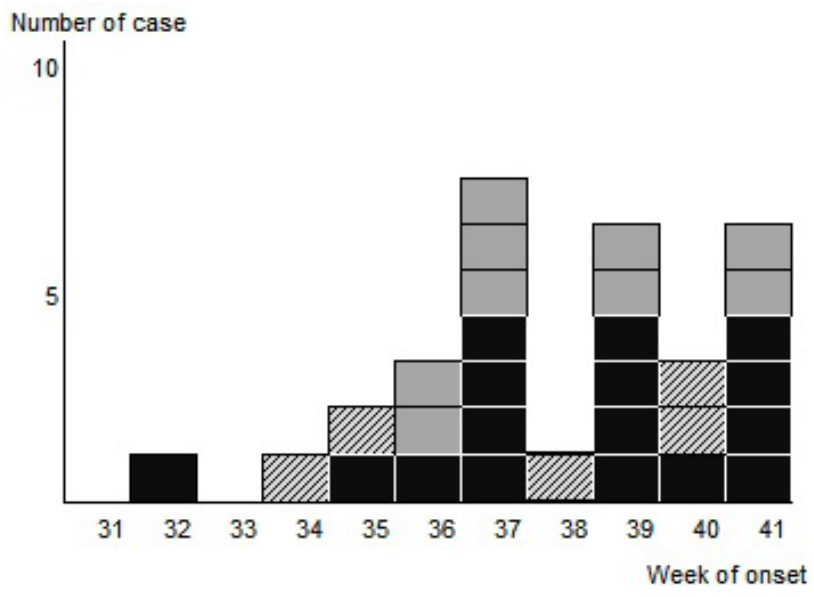

Tsinjoarivo Imanga

Ambatolampy

Other municipalities

Figure 1: Plague cases by locality according to week of onset in the district of Tsiroanomandidy, August 1st until October 12th, 2014 (week 32 to week 41) $(\mathrm{n}=30)$

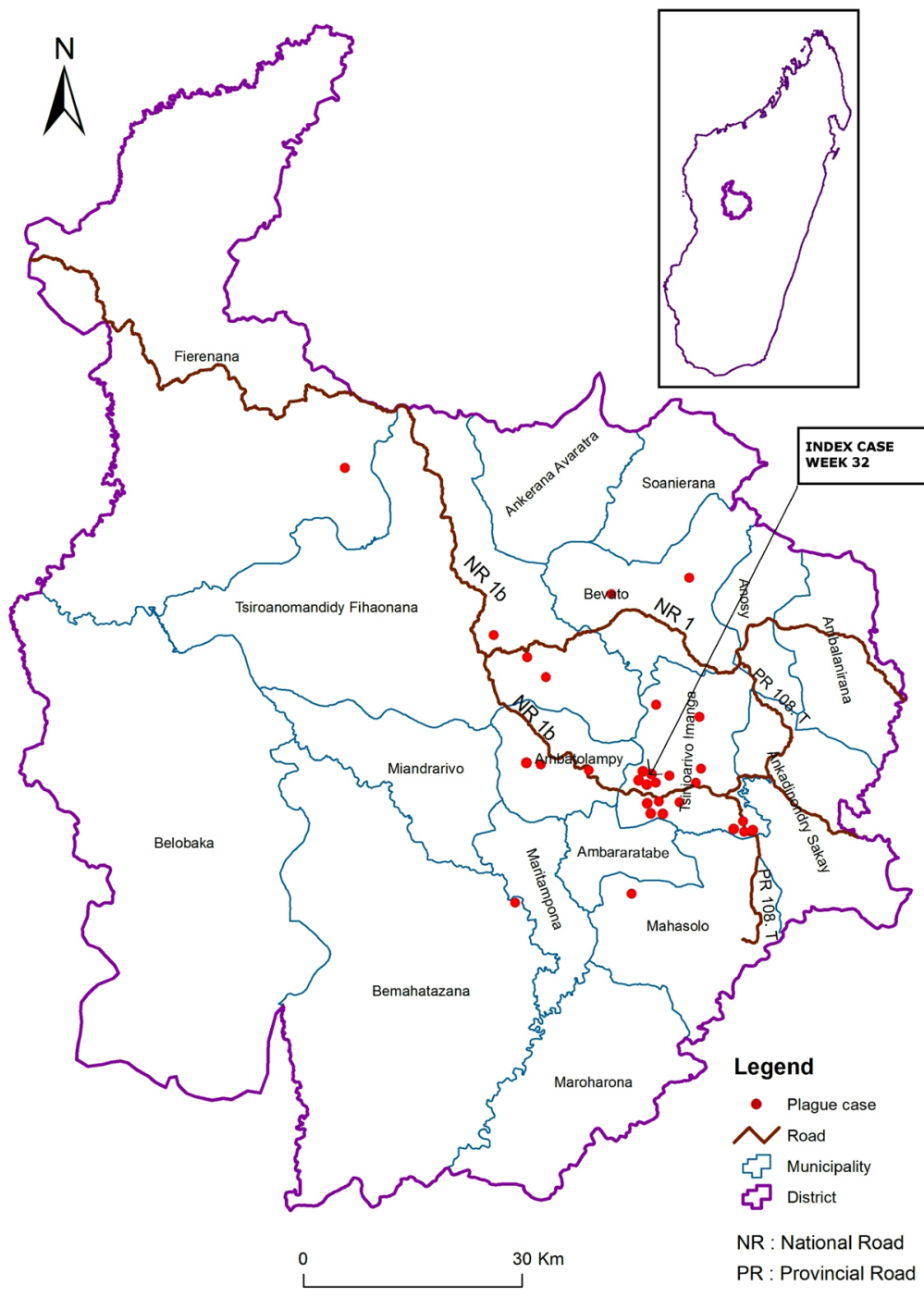

Figure 2: Tsiroanomandidy reported cases of plague

\section{Reservoirs and vectors}

A total of 145 small rodents were trapped in 5 hamlets with human cases. Rodent spleen samples were tested for plague by culture on median agar. Sampling was conducted in accordance with the Pasteur Institute guidelines.

There were 4 positive in Yersinia pestis isolation among the 48 Rattus rattus dissected. The flea index was 2.3. 
Forty-five fleas were collected by a flee trap set 6 hours after insecticide spraying in the house of deceased of plague cases in the municipality of Ambatolampy.

\section{Discussion}

Tsiroanomandidy is known as a plague endemic district even if not all of its municipalities are affected. During our investigation, seven out of the 17 municipalities of Tsiroanomandidy reported cases of plague and these four municipalities were ranked among the areas with a total number over 40 plague cases for the last six years (2008-2014). Two municipalities (Tsinjoarivo Imanga and Ambatolampy) accounted for $90 \%$ of registered cases.

The distribution of case (Table 1) suggests that there is no specific cluster of cases by locality, and cases have been distributed over several weeks in each. Nearly half of the cases deceased (13/30, i.e. $42 \%)$, this high case fatality in the three hamlets may be related to late detection of cases and poor healthcare systems, particularly in remote areas with limited access of care. Population uses primarily traditional healers $[11,12]$. The documented case fatality for bubonic plague is 5 to $10 \%[13,14]$. All cases died at home and did not seek treatment at the health center.

In this outbreak the majority of cases were young men, with a median age of 15 years, and children. Sex ratio ( M / F) was 4: 1, in the rural area, boys used to keep the cattle in the fields and men often leave home to work in the fields or even in other regions with high exposure to wild rodents $[11,13,15]$.

The scarcity of rodents captured suggests probable epizootics that occurred before the beginning of the human plague. The presence of positive rodents to the rapid plague test (F1 dipstick assay) during the investigation showed that epizootics were still active in these municipalities. The flea index greater than 2.3 is potentially a condition increasing the risk of plague transmission to humans $[3,16,17]$. Consequently, it requires particular monitoring and control measures of rodents and vectors.

Insecticides used appeared to be inefficient, which may be attributed to the insecticide flea resistance or an inaccuracy of spreading technique but also a possible deterioration of the product due to poor conservation. This may be the cause of the increase number of cases in some districts [18-21]. Consequently, tests to determine sensitivity of flea population to insecticides must be conducted periodically and staff that makes the spreading should be trained periodically and provided with adequate equipment. Moreover insecticides must be protected from light and moisture.

Limitations of this study are the potential false negative due to sampling technique on the field, impacting in biological results because the technique of handling the rapid test and the puncture of the bubo might be difficult for non-trained personnel.

\section{Conclusion}

The presence of infected flea and rodent during the investigation confirmed that Yersinia pestis was still circulating in this area and the high flea index is a potentially condition to increase the risk of plague transmission to humans. Information concerning the reservoirs and vectors are of great utility to the plague control measures. In this investigation we were able to localize villages or hamlets with active plague focus, but also problems on the effectiveness of insecticides using information obtained about the reservoirs and vectors investigations.

We suggest to systematically performing rodents and vectors elimination in all plague endemic districts before the beginning of plague season especially in August. Controlled use of insecticides and also the periodical training of spraying agents are necessary.

Positioning of antibiotic stocks in remote areas would shorten the delay of treatment administration.

The population should be sensitized on symptoms of plague and educated about procedures in case of plague suspicion by the local health staff in collaboration with the community leaders in the village.

Establishment of surveillance in each village involving community focal point would allow early detection and reporting of rat mortality and suspicious deaths. The focal point could meanwhile ensure that all patients come to the health center immediately at the beginning of the symptoms.

\section{Acknowledgment}

We are deeply indebted to the Malagasy Ministry of Public Health as well as the staff located at the district of Tsiroanomandidy. Epidemiological and laboratory data collection were made possible through dedicated work from staffs from the plague control department of $\mathrm{MOH}$ and Plague laboratory Pasteur Institute of Madagascar.

This publication was supported by the internal fund of Pasteur Institute of Madagascar and the Ministry of Health of Madagascar.

\section{References}

1. Butler T (2016) Plague Gives Surprises in the First Decade of the 21st Century in the United States and Worldwide. Am J Trop Med Hyg 89: 788-93. 
2. Dennis DT, Gage KL (1999) Manual of plague: epidemiology, distribution, surveillance and struggle [Manuel de la peste Epidémiologie, répartition, surveillance et lutte], USA.

3. Plague Atlas in Madagascar Plague Study Group (2004) [Atlas de la peste à Madagascar Groupe d'Etudes sur la Peste], Institut Pasteur de Madagascar, Madagascar. 4. World Health Organization (2016) Weekly epidemiological record [Relevé épidémiologique hebdomadaire].

5. Handschumacher P, Duplantier JM, Chanteau S (2000) The resurgence of the plague in Madagascar: a 100-year-old disease with history and ecology [La résurgence de la peste à Madagascar : une maladie centenaire à l'épreuve de l'histoire et de l'écologie], Espaces, Populations Societés.

6. Kannapel P, Amat-Roze JM (2005) On the paths of plague in Madagascar, Mémoire DEA 2005 [Sur les chemins de la peste a Madagascar, Mémoire DEA 2005].

7. Ministry of Health The National Policy for the Fight Against Plague [Ministère de la Santé. La politique Nationale de Lutte contre la peste], Madagascar.

8. Chanteau S, Rahalison L, Ratsitorahina M, Mahafaly, Rasolomaharo M, et al. (2000) Early diagnosis of bubonic plague using F1 antigen capture ELISA assay and rapid immunogold dipstick. Int J Med Microbiol 290: 279-83.

9. Pasteur (2016) Institute Pasteur Ethics Charter, France.

10. National Institute of Statistics Ministry of Economy and Industry [Institut National de la Statistique Ministère de l'Économie et de l'Industrie] (2009) Demographic and Health Survey Madagascar [Enquête Démographique et de Santé Madagascar] (EDSM 2009), Madagascar.

11. Ratsitorahina M, Migliani R, Ratsifasoamanana L, Ratsimba M, Chan Ho Thin (2001) Recrudescence and spread of plague in Madagascar from 1980 to 1999 [Recrudescence et extension géographique de la peste à Madagascar de 1980 à 1999] Arch Inst Pasteur de Madagascar 67: 14-8.

12. Ratsifasoamanana L, Rasoamanana B, Randriambelosoa J, Roux JF, Chanteau S (1998) Plague, a re-emerging disease in Madagascar [La peste : maladie réémergence à Madagascar]. Arch Inst Pasteur Madagascar 1: 12-4.

13. Rakotoarisoa A, Ravaoarisoa L, Rakotomanga JDM (2007) Plague: the factors of endemisation of the endemic in the district of Antsirabe II [Peste: les facteurs de pérennisation de l'endémie dans le district d’Antsirabe II]. Mém. Santé Pub 71.

14. Chanteau S, Ratsitorahina M, Rahalison L, Rasoamanana B, Chan F (2000) Current epidemiology of human plague in Madagascar. Microbes Infect 2: 25-31.

15. Migliani R, Chanteau S, Rahalison L, Ratsitorahina M, Boutin JP, et al. (2006) Epidemiological trends for human plague in Madagascar during the second half of the 20th century: a survey of 20,900 notified cases. Trop Med Int Health 11: 1228-37.

16. Duplantier J, Laventure S, Rahalison L (1999) From rural plague without a wild reservoir to urban plague without rodents: the Malagasy paradox [De la peste rurale sans réservoir sauvage à la peste urbaine sans rongeurs : le paradoxe Malagache]. Arch Inst Past Mad 65.

17. Brossolet J, Mollaret HH (1994) Pourquoi la peste? le rat, la puce, et le bubon; Decouvertes Gallimard n²29, Gallimard Paris, France.

18. Chanteau S, Ratsifasoamanana L, Rasomanana B, Rahalison L, Randriambelosoa J, et al. (1998) Plague, a reemerging disease in Madagascar. Emerg Infect Dis 4: 101-4.

19. Rahalison L (2011) Murine surveillance mission report of the Pasteur Institute of Madagascar in the fokontany plague center of the district of Antsirabe II [Rapport de mission de surveillance murine de l'Institut Pasteur de Madagascar dans les fokontany foyer de peste du district d'Antsirabe II].

20. Tollenaere C, Duplantier JM, Sorci G, Wirth T (2009) Génétique et évolution du rat noir, Rattus rattus, réservoir de la peste à Madagascar.

21. World Health Organization (1970) World Health Organization Expert Committee on plague, Fourth report, WHO technical report series.

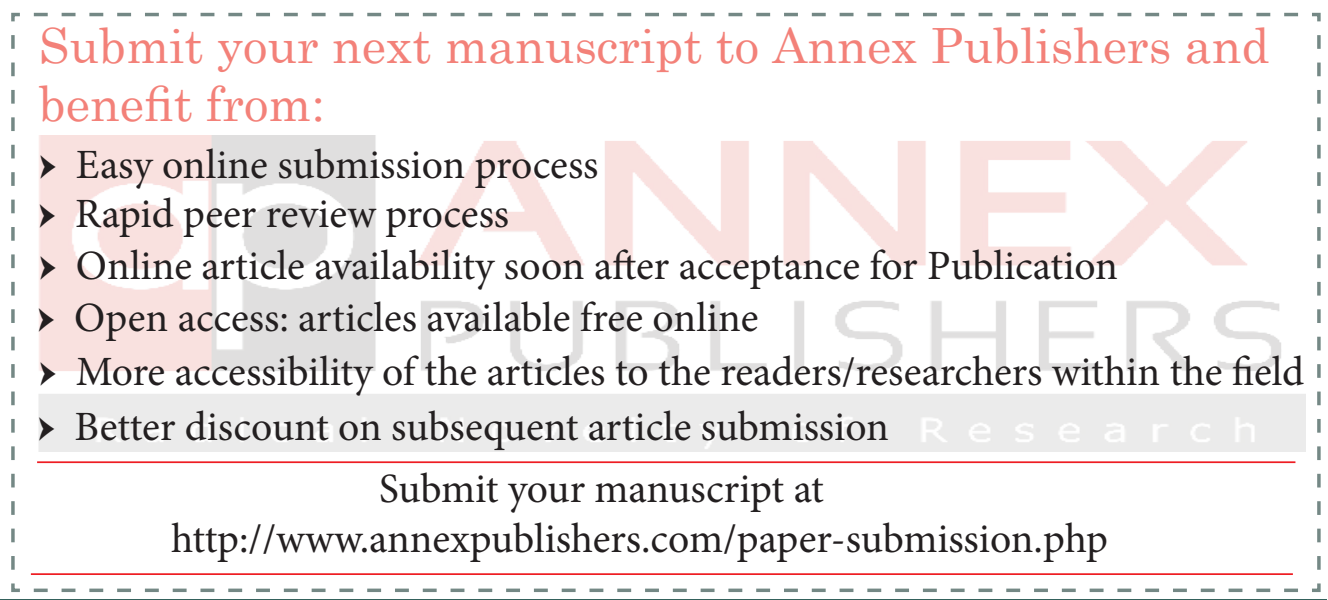

